\title{
Selective Detection of Acetone Vapor Using Hydrophobized Pillared Carbon Thin Films
}

\author{
Yoshiaki Matsuo* and Masanobu Araki \\ Department of Applied Chemistry, Graduate School of Engineering, University of Hyogo, Hyogo, Japan
}

Pillared carbon thin films were prepared from the thermal reduction of graphite oxide silylated with octyltrichlorosilane and then dimethyldichlorosilane. The interlayer spacing of the resulting pillared carbon thin film was $1.29 \mathrm{~nm}$, and it contained hydrophobic $\mathrm{Si}-\mathrm{CH}_{3}$ groups, excluding $\mathrm{Si}-\mathrm{OH}$ ones. The resistance of it increased during the exposure to acetone vapor, while it was unchanged when it was exposed to the water vapor. Moreover, in the presence of water vapor, the resistance changed in a similar manner.

Keywords: pillared carbon, silylation, graphite oxide, thin film, acetone gas sensor

\section{INTRODUCTION}

OPEN ACCESS

Edited by:

Emilia Morallon,

University of Alicante, Spain

Reviewed by:

Santosh K. Yadav,

Drexel University, United States

Thiagarajan Soundappan,

Navajo Technical University,

United States

*Correspondence:

Yoshiaki Matsuo

ymatsuo@eng.u-hyogo.ac.jp

Specialty section:

This article was submitted to Carbon-Based Materials,

a section of the journal

Frontiers in Materials

Received: 12 April 2017 Accepted: 13 June 2017 Published: 30 June 2017

Citation:

Matsuo Y and Araki M (2017) Selective Detection of Acetone Vapor

Using Hydrophobized Pillared Carbon Thin Films.

Front. Mater. 4:17.

doi: 10.3389/fmats.2017.00017
Recently, the development of portable breath monitoring sensor becomes highly important in the healthcare field. Exhaled breath contains various molecules that hold great promise for monitoring health. For example, the amount of exhaled acetone increases when we get diabetes. Various gas sensors are so far proposed for selective detection of acetone. Selectivity toward acetone detection have been achieved by using (002) facet of $\mathrm{WO}_{3}$ (Ji et al., 2014), multiwalled carbon nanotube coated with $\mathrm{SnO}_{2}$ (Aroutiounian et al., 2015), non-stationarity temperature regime (Shaposhnik et al., 2014), zeolite concentrator (Yamada et al., 2015), etc. However, in case of the use of semiconductors, such as $\mathrm{WO}_{3}$ and $\mathrm{SnO}_{2}$, high temperature is needed for detection and, therefore, heating system should be installed in the sensor.

On the other hand, we have recently reported the preparation of pillared carbon thin films, showing size selective gas detection properties at room temperature (Matsuo et al., 2012, 2014). Pillared carbon is consisting of graphene layers connected with silsesquioxane type pillars. It shows size selective intercalation of organic molecules, depending on the size of the space available between adjacent pillars and graphene layers (Matsuo and Konishi, 2011, 2012; Matsuo et al., 2012, 2014). However, to detect acetone molecules in exhaled breath, selective detection of it in the presence of water molecules should be needed. However, the strategy of size selective detection can not be applied for this purpose because the molecular size of the acetone is larger than that of water. In this study, therefore, to achieve the selectivity for the detection of acetone in the presence of water, we tried to prepare pillared carbon thin films containing hydrophobic pillars by using graphite oxide silylated with dimethyldichlorosilane as a precursor.

\section{MATERIALS AND METHODS}

Preparation of pillared carbon thin films with hydrophobic pillars was performed in a similar manner as reported in our previous studies (Matsuo et al., 2012, 2014). Graphite oxide was prepared from natural graphite powder (average diameter of $5 \mu \mathrm{m}$ ) in a fuming nitric acid using potassium chlorate, based on the Brodie's method (Brodie, 1859). The composition of the resulting $\mathrm{GO}$ was $\mathrm{C}_{8} \mathrm{H}_{2.9} \mathrm{O}_{4.9}$. GO $(100 \mathrm{mg})$ was mixed with $n$-butylamine $\left[\mathrm{C}_{4} \mathrm{H}_{9} \mathrm{NH}_{2}\right.$, hereafter abbreviated as $\mathrm{C}_{4}, 1.78 \mathrm{~mL} ; 32 \mathrm{~mol}$ 
per $\mathrm{GO}$ unit $\left.\left(\mathrm{C}_{8} \mathrm{H}_{2.9} \mathrm{O}_{4.9}\right)\right]$ as an exfoliating reagent in a sealed glass vial under an Ar atmosphere, and the resulting solution was sonicated for $15 \mathrm{~min}$ (VELVO-CLEAR, VS-150; $50 \mathrm{kHz}, 150 \mathrm{~W}$ ), then heated at $60^{\circ} \mathrm{C}$ for $1 \mathrm{~h}$. Dry toluene $(5 \mathrm{~mL}$, water content $<30 \mathrm{ppm})$ was added to this solution. Silylating reagent (octyltrichlorosilane, $\mathrm{C}_{8} \mathrm{H}_{17} \mathrm{SiCl}_{3}$ : hereafter $\mathrm{C}_{8} \mathrm{Si}, 1.70 \mathrm{~mL}$ ) was added to the resulting solution and then allowed to stand for 1 day at $60^{\circ} \mathrm{C}$. After centrifugation, the precipitate was washed with dry toluene, ethanol, and finally acetone. The obtained silylated GO sample is denoted as $\mathrm{C}_{8} \mathrm{SiGO}$. $n$-Hexadecylamine was added to the $\mathrm{C}_{8} \mathrm{SiGO}$ in the presence of a small amount of hexane and ground in a pestle until it evaporated. The mixture was heated at $60^{\circ} \mathrm{C}$ overnight. It was then dispersed in cyclohexane/chloroform (1:1 by volume) and then cast on a glass or $\mathrm{Si}$ plate. The resulting thin films of $\mathrm{C}_{8} \mathrm{SiGO}$ were then silylated with dimethyldichlorosilane [abbreviated as $\left(\mathrm{C}_{1}\right)_{2} \mathrm{Si}$. The $\mathrm{C}_{8} \mathrm{SiGO}$ thin films were placed in a vial containing toluene $(4 \mathrm{~mL})$ and $\left(\mathrm{C}_{1}\right)_{2} \mathrm{Si}(0.4 \mathrm{~mL})$ were added, and then allowed to stand at $60^{\circ} \mathrm{C}$ for 1 day. For comparison, $\mathrm{C}_{8} \mathrm{SiGO}$ thin films were also silylated with 3-aminoproopyltirethoxysialne (APS, $0.25 \mathrm{~mL}$ ) or methyltrichlorosilane $\left(\mathrm{C}_{1} \mathrm{Si}, 0.2 \mathrm{~mL}\right)$ for 6 or $24 \mathrm{~h}$. The resulting samples are denoted as $\mathrm{C}_{8} \mathrm{SiGO}-\left(\mathrm{C}_{1}\right)_{2} \mathrm{Si}, \mathrm{C}_{8} \mathrm{SiGO}-$ APS, and $\mathrm{C}_{8} \mathrm{SiGO}-\mathrm{C}_{1} \mathrm{Si}$, respectively. They are then heated under vacuum at $500^{\circ} \mathrm{C}$ for $5 \mathrm{~h}$. The obtained samples were analyzed by $\mathrm{X}$-ray diffraction (Rigaku Rint-2100 or Bruker D2Phaser, CuK $\alpha$ ) and IR (Nicolet iS50). The IR spectra were obtained for the samples prepared on Si substrates. SEM observation was performed by using JEOL JSM-6010PLUS/LV.
Figure 1A shows the apparatus for gas sensing tests of pillared carbon thin films (Matsuo et al., 2012, 2014), together with the pillared carbon sample with copper plates as electrical terminals (Figure 1B) and the SEM image of a typical pillared carbon film (Figure 1C). Some wrinkles are observed on the surface of the film; however, it was rather smooth and grain boundaries were not well visible. After evacuating the container (9 L), appropriate amounts of liquid water, acetone, or the mixture of them were injected to it, and they are evaporated. The current was recorded during the application of constant voltage of $1.9 \mathrm{~V}$ to the film sample when it was exposed to water, acetone or the mixture of them. After the pillared carbon film samples were exposed to each vapor for the measurement of electrical response, the container was evacuated for $30 \mathrm{~min}$ to remove the adsorbed molecules. The concentrations of water or acetone vapors were 1,000 ppm, and in case of the mixture of acetone and water, both of them were $1,000 \mathrm{ppm}$.

\section{RESULTS AND DISCUSSION}

Figure 2 shows the $\mathrm{X}$-ray diffraction patterns of $\mathrm{C}_{8} \mathrm{SiGO}$ film, and those silylated with $\left(\mathrm{C}_{1}\right)_{2} \mathrm{Si}, \mathrm{C}_{1} \mathrm{Si}$, and APS. The diffraction peak of $\mathrm{C}_{8} \mathrm{SiGO}$ film observed at $2 \theta=5.24^{\circ}(d=1.69 \mathrm{~nm})$ shifted to lower angles of $2 \theta=3.79(d=2.33 \mathrm{~nm}), 3.73(d=2.37 \mathrm{~nm})$, and $3.22^{\circ}$ $(d=2.66 \mathrm{~nm})$ when it was silylated with $\left(\mathrm{C}_{1}\right)_{2} \mathrm{Si}, \mathrm{C}_{1} \mathrm{Si}$, and APS, respectively, which means that the $\mathrm{C}_{8} \mathrm{SiGO}$ film was successfully silylated. Figure 3 shows the X-ray diffraction patterns of the

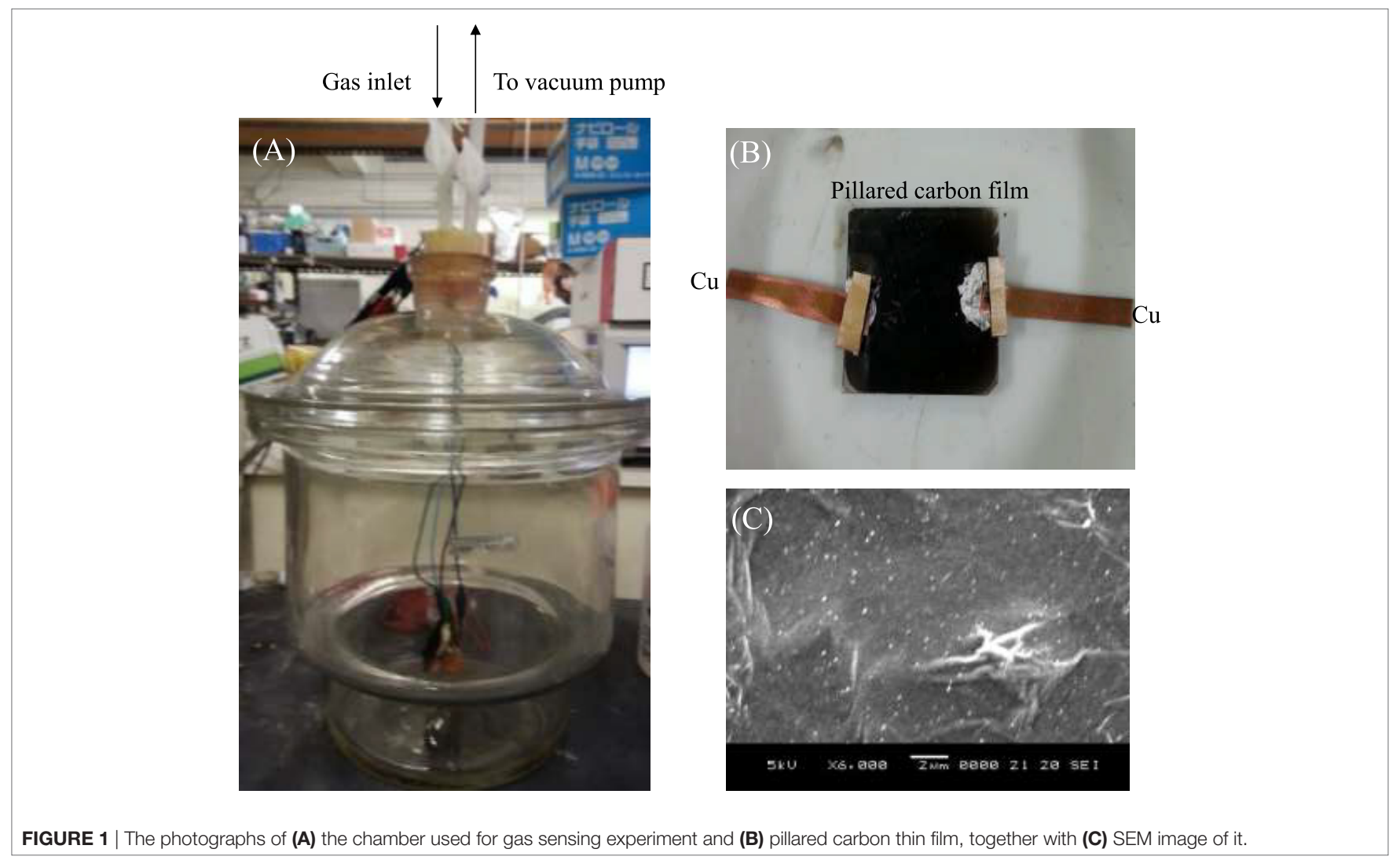




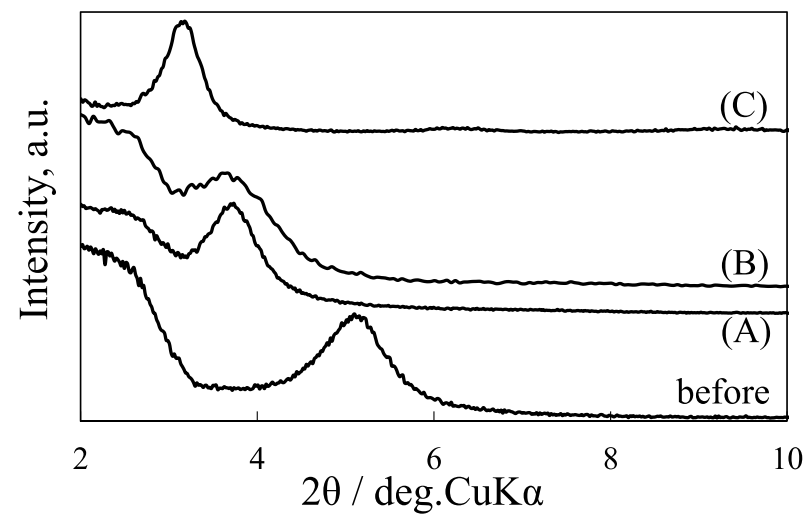

FIGURE 2 |X-ray diffraction patterns of $\mathrm{C}_{8} \mathrm{SiGO}$ before and after silylated with (A) $\left(\mathrm{C}_{1}\right)_{2} \mathrm{Si}$, (B) $\mathrm{C}_{1} \mathrm{Si}$, and (C) APS.

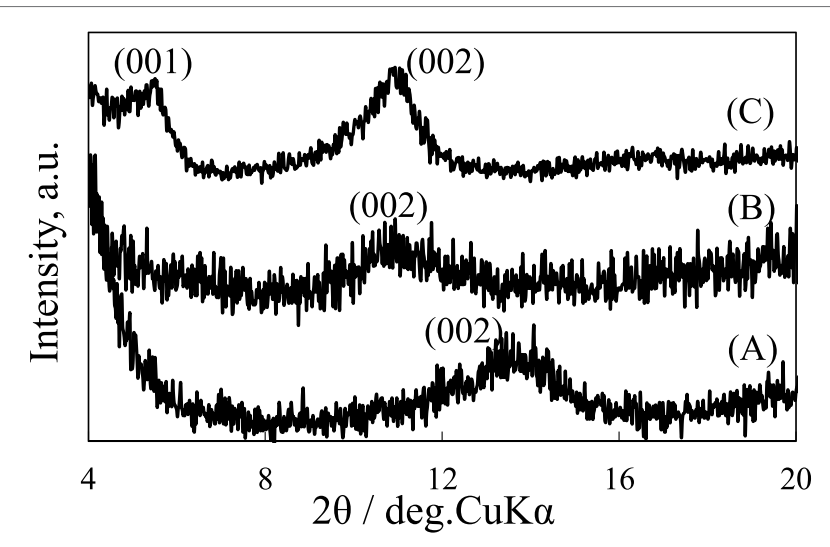

FIGURE 3 | X-ray diffraction patterns of pillared carbons obtained from (A) $\mathrm{C}_{8} \mathrm{SiGO}-\left(\mathrm{C}_{1}\right)_{2} \mathrm{Si}$, (B) $\mathrm{C}_{8} \mathrm{SiGO}-\mathrm{C}_{1} \mathrm{Si}$, and (C) $\mathrm{C}_{8} \mathrm{SiGO}-\mathrm{APS}$.

above silylated $\mathrm{C}_{8} \mathrm{SiGO}$ films after heat treated at $500^{\circ} \mathrm{C}$. In case of $\mathrm{C}_{8} \mathrm{SiGO}-\mathrm{C}_{1} \mathrm{Si}$ and $\mathrm{C}_{8} \mathrm{SiGO}-\left(\mathrm{C}_{1}\right)_{2} \mathrm{Si}$, the diffraction peaks at lower angles disappeared and those at $2 \theta=13.73(d=0.65 \mathrm{~nm})$ and $10.85^{\circ}(d=0.82 \mathrm{~nm})$ were observed, respectively and no peak appeared around $2 \theta=25^{\circ}$ due to residual carbon (not shown). This means that pillared carbon was successfully prepared. Since the (002) lines are most strongly observed for the other pillared carbons, these are also indexed as (002) lines, and the interlayer spacings of 1.39 and $1.63 \mathrm{~nm}$ are obtained. On the other hand, two diffraction peaks at $2 \theta=5.55(d=1.592 \mathrm{~nm})$ and $11.04^{\circ}$ ( $d=8.01 \mathrm{~nm})$ were observed for $\mathrm{C}_{8} \mathrm{SiGO}$-APS. These can be indexed as (001) and (002) lines, therefore, the interlayer spacing is calculated to be $1.60 \mathrm{~nm}$.

Figure 4 shows the IR spectra of the pillared carbon thin films. The absorption peaks at 1,050 and $1,150 \mathrm{~cm}^{-1}$ were commonly observed, which are ascribed to the $\mathrm{Si}-\mathrm{O}-\mathrm{Si}$ symmetric and asymmetric stretching vibrations in pillars, respectively. The peaks at 950 and $1,270 \mathrm{~cm}^{-1}$ due to $\mathrm{Si}-\mathrm{OH}$ and $\mathrm{Si}-\mathrm{CH}_{3}$ were observed for the pillared carbon obtained from $\mathrm{C}_{8} \mathrm{SiGO}-\mathrm{C}_{1} \mathrm{Si}$ film silylated with, however, only the former or the latter was

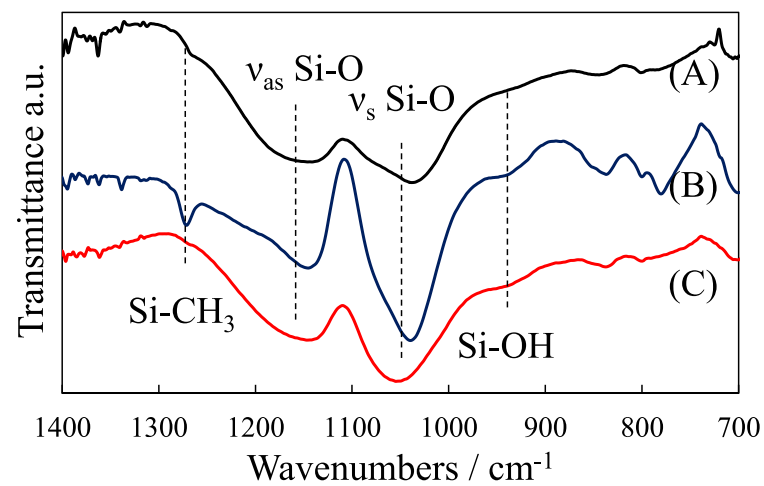

FIGURE 4 | IR spectra of pillared carbons obtained from (A) $\mathrm{C}_{8} \mathrm{SiGO}-\left(\mathrm{C}_{1}\right)_{2} \mathrm{Si}$, (B) $\mathrm{C}_{8} \mathrm{SiGO}-\mathrm{C}_{1} \mathrm{Si}$, and (C) $\mathrm{C}_{8} \mathrm{SiGO}-\mathrm{APS}$.

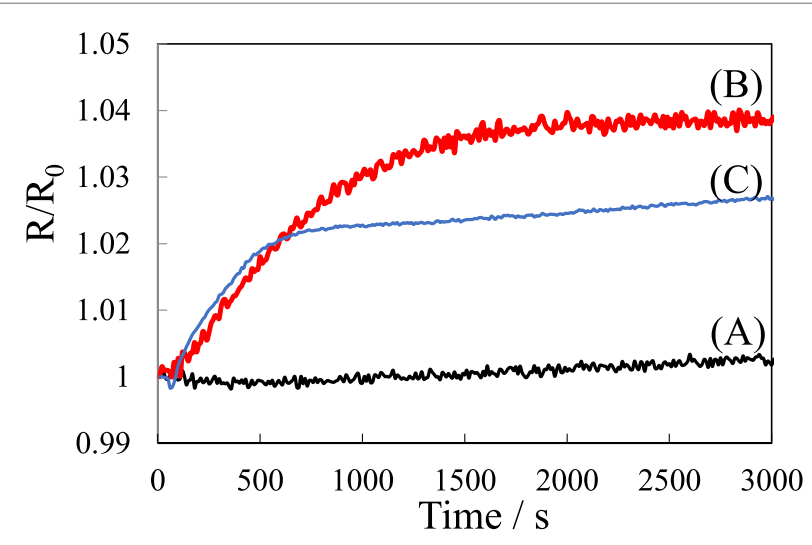

FIGURE 5 | Electrical response of pillared carbons obtained from (A) $\mathrm{C}_{8} \mathrm{SiGO}-\left(\mathrm{C}_{1}\right)_{2} \mathrm{Si}$, (B) $\mathrm{C}_{8} \mathrm{SiGO}-\mathrm{C}_{1} \mathrm{Si}$, and $(\mathrm{C}) \mathrm{C}_{8} \mathrm{SiGO}-\mathrm{APS}$ during exposure to water vapor.

observed for those from APS- or $\mathrm{C}_{8} \mathrm{SiGO}-\left(\mathrm{C}_{1}\right)_{2} \mathrm{Si}$, respectively. This indicates that the most hydrophobic pillared carbon was obtained when it is prepared from $\mathrm{C}_{8} \mathrm{SiGO}-\left(\mathrm{C}_{1}\right)_{2} \mathrm{Si}$.

Figure 5 shows the variation of $R / R_{0}$ values of the pillared carbon thin film during exposure to water vapor. It increased for the pillared carbon of obtained from $\mathrm{C}_{8} \mathrm{SiGO}-\mathrm{C}_{1} \mathrm{Si}$ and $\mathrm{C}_{8} \mathrm{SiGO}-\mathrm{APS}$ in a similar manner and reached almost constant values after 600 and $1,500 \mathrm{~s}$, respectively. As previously reported, the resistance of pillared carbon increases upon electron donating molecules (Matsuo et al., 2012, 2014); therefore, this result indicates that water molecules were adsorbed on these pillared carbons. On the other hand, the $R / R_{0}$ value was almost constant for pillared carbon from $\mathrm{C}_{8} \mathrm{SiGO}-\left(\mathrm{C}_{1}\right)_{2} \mathrm{Si}$ as expected from the hydrophobic nature of this sample. The small change in the $R / R_{0}$ values may be ascribed to the surface morphology of the present samples as shown in Figure 1C. Few grain boundaries existing on the surface of the film made it difficult for gaseous molecules to enter the interlayer space of the pillared carbon.

Figure 6 shows the variation of $R / R_{0}$ values of the pillared carbon thin film during exposure to acetone, and the mixture 


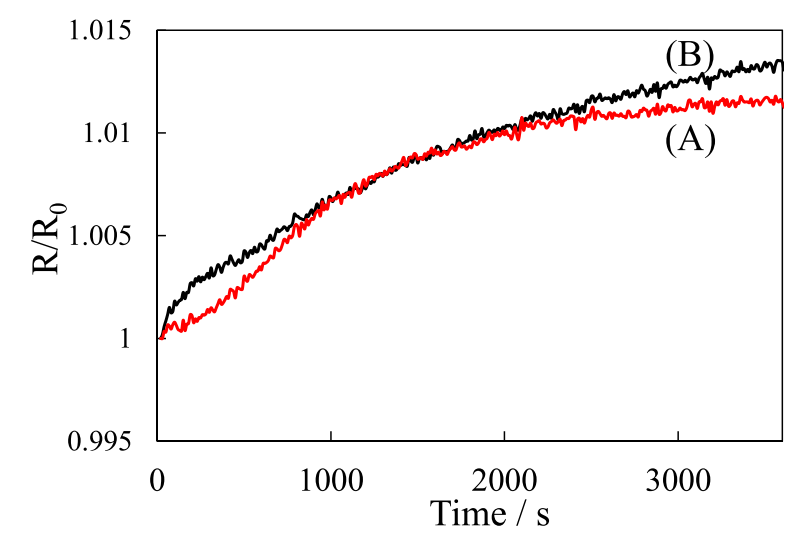

FIGURE 6 | Electrical response of pillared carbon obtained from $\mathrm{C}_{8} \mathrm{SiGO}$ $\left(\mathrm{C}_{1}\right)_{2} \mathrm{Si}$, during exposure to the vapors of $(\mathrm{A})$ acetone and $(\mathrm{B})$ the mixture of water and acetone.

of water and acetone vapors. Upon the exposure to acetone, it gradually increased, which means that acetone molecules are successfully detected, though the change in the $R / R_{0}$ value was very small. Moreover, even in the presence of water vapor, the $R / R_{0}$ values changed in an almost similar manner. This clearly shows that selective detection of acetone molecules was achieved.

Figure 7 shows the X-ray diffraction patterns of pillared carbon from $\left(\mathrm{C}_{1}\right)_{2} \mathrm{Si}-\mathrm{C}_{8} \mathrm{SiGO}$ before and after immersion in acetone and water. Here, the measurement was performed before the liquid on the sample completely evaporated. The diffraction peak observed for the pristine pillared carbon at $2 \theta=13.73^{\circ}$ was observed at almost the same position even after immersion in water. On the other hand, this peak disappeared when the pillared carbon was immersed in acetone and a very broad peak appeared around $2 \theta=8^{\circ}(d=1.1 \mathrm{~nm})$. These results suggest that acetone molecules entered the interlayer space of pillared carbon; however, smaller water molecules were intercalated into the interlayer space of pillared carbon. The hydrophobic nature of the pillars in the pillared carbon obtained from and $\mathrm{C}_{8} \mathrm{SiGO}-$ $\left(\mathrm{C}_{1}\right)_{2} \mathrm{Si}$ as expected from the IR spectrum prevented the water molecules from intercalation. On the other hand, the methyl groups in acetone can interact with those in pillars to enter

\section{REFERENCES}

Aroutiounian, V. M., Adamyan, Z. N., Sayunts, A. G., Khachaturyan, E. A., and Adamyan, A. Z. (2015). "Study of $\mathrm{MWCNT} / \mathrm{SnO}_{2}$ nanocomposite acetone and toluene vapor sensors," in AMA Conferences, Nuremberg, 836-841.

Brodie, B. C. (1859). On the atomic weight of graphite. Philos. Trans. R. Soc. Lond. 149, 249-259. doi:10.1098/rstl.1859.0013

Ji, Q., Ji, H., Wang, D., Bai, X., Sun, X., and Jin, Z. (2014). Exposed facets induced enhanced acetone selective sensing property of nanostructured tungsten oxide. J. Mater. Chem. A 2, 13602-13611. doi:10.1039/C4TA01930J

Matsuo, Y., Iwasa, K., Mimura, T., and Tachibana, Y. (2014). Preparation of pillared carbon thin films from the reduction of silylated graphite oxide by UV light irradiation and their size selective electrical response to various molecules. Carbon N. Y. 75, 271-276. doi:10.1016/j.carbon.2014.04.001

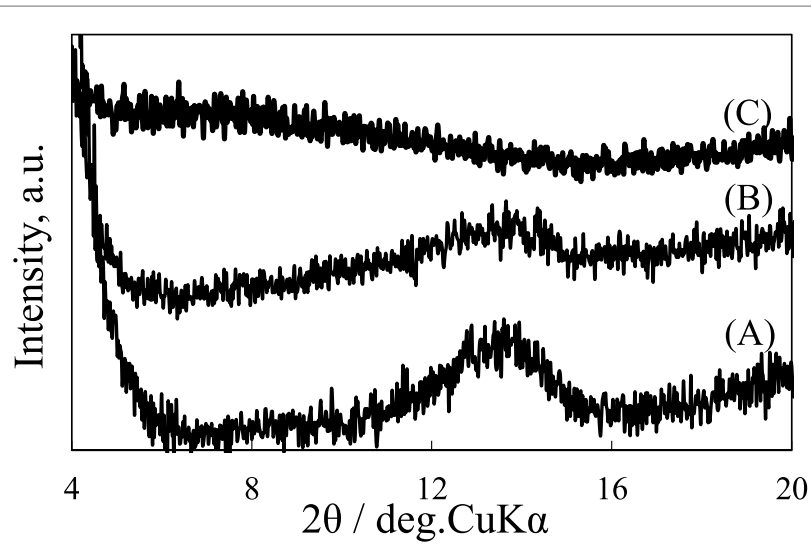

FIGURE 7 | X-ray diffraction patterns of pillared carbons obtained from $\mathrm{C}_{8} \mathrm{SiGO}-\left(\mathrm{C}_{1}\right)_{2} \mathrm{Si}(\mathrm{A})$ before, and after immersion in $(\mathrm{B})$ water and $(\mathrm{C})$ acetone.

the interlayer space of pillared carbon. In such a case, carbonyl groups in them interact with carbon layers to achieve charge transfer and the resistance of the film can change. This leads to the selective detection of acetone molecules.

In conclusion, pillared carbon thin film was successfully obtained from the thermal reduction of graphite oxide silylated with octyltrichlorosilane and then dimethyldichlorosilane. The pillars of the resulting pillared carbon were hydrophobic and prevented the intercalation of smaller water molecules. By using this pillared carbon thin film, the selective detection of acetone was achieved in the presence of water vapor. The sensitivity and response time of this film are still very low; however, they would be improved by reducing the size of graphene sheets, optimizing the structure of sensor, etc.

\section{AUTHOR CONTRIBUTIONS}

All authors listed have made a substantial, direct and intellectual contribution to the work, and approved it for publication.

\section{FUNDING}

This work was supported by JSPS KAKENHI Grant Number JP25410242.

Matsuo, Y., and Konishi, K. (2011). Size-dependent inclusion of organic molecules into elastic pillared carbons. Chem. Commun. 47, 4409-4411. doi:10.1039/ c0cc05552b

Matsuo, Y., and Konishi, K. (2012). Intercalation of various organic molecules into pillared carbon. Carbon N. Y. 50, 2280-2286. doi:10.1016/j.carbon. 2012.01.047

Matsuo, Y., Tachibana, Y., and Konishi, K. (2012). Preparation of pillared carbon thin films and their size selective electrical response to organic vapor. Carbon N. Y. 50, 5346-5348. doi:10.1016/j.carbon.2012.07.013

Shaposhnik, A., Zviagin, A., Sizask, E., Ryabtsev, S., Vasiliev, A., and Shaposhnik, D. (2014). Acetone and ethanol selective detection by a single MOX-sensor. Proc. Eng. 87, 1051-1054. doi:10.1016/j.proeng.2014.11.343

Yamada, Y., Hiyama, S., Toyooka, T., Takeuchi, S., Itabashi, K., Okubo, T., et al. (2015). Ultratrace measurement of acetone from skin using zeolite: toward 
development of a wearable monitor of fat metabolism. Anal. Chem. 87, 7588-7594. doi:10.1021/acs.analchem.5b00296

Conflict of Interest Statement: The authors declare that the research was conducted in the absence of any commercial or financial relationships that could be construed as a potential conflict of interest.
Copyright $\odot 2017$ Matsuo and Araki. This is an open-access article distributed under the terms of the Creative Commons Attribution License (CC BY). The use, distribution or reproduction in other forums is permitted, provided the original author(s) or licensor are credited and that the original publication in this journal is cited, in accordance with accepted academic practice. No use, distribution or reproduction is permitted which does not comply with these terms. 